\title{
Pathways of Psychiatric Treatment in Rural Patients with Psychosis
}

\author{
Vikas Kumar \& Manisha Kiran
}

\section{ABSTRACT}

Background : Pathways of care support the development of care partnerships and empower patients and their care providers along with necessary modifications in the existing health services.

Aim : To examine the various pathways of psychiatric treatment in rural patients with psychosis and to know the source of referral, first contact for treatment, awareness about the signs and symptoms and various symptoms (complains) with which the patients presented themselves to the different modalities of treatment.

Methods : It was a cross sectional hospital based study conducted at Out-Patient Department of Ranchi Institute of Neuro-Psychiatry \& Allied Sciences (RINPAS) Kanke, Ranchi. Purposive sampling technique was used for the study, total 96 participants were selected in 1 month duration. Subjects were evaluated using socio demographic datasheet, WHO counter form and BPRS-24.

Results : The present study found that the mean duration of untreated psychosis was $558.80 \pm 707.08$ days. First symptoms appeared at onset of illness, in which fearfulness $(13.5 \%)$ appeared in most patients. Time taken to decide to go for consultation after onset of illness was $417.67 \pm 621.11$ days. Maximum first consultations were to native \& faith healers $(69.8 \%)$ and only $17.7 \%$ consulted psychiatric services at first contact. For the first referral, $64.6 \%$ patients shifted to psychiatric services from other modes such as native / faith healer, general hospital and medical practitioner.

CONCLUSION : The study provides an insight into the nature of the pathway and referral taken by rural patients with psychosis and their caregivers.

Key Words : Pathways, Psychiatric treatment, rural patients.

\section{INTRODUCTION :}

According to $\mathrm{WHO}$, health is not only the absence of disease or infirmity but it is a state of complete physical, mental and social well-being. ${ }^{[1]}$ If we go through the definition, we find that there are three ideas central to the improvement of health - physical, mental and social well being. Mental health is an integral part of health, mental health is more than the absence of mental illness, and mental health is intimately connected with physical health and behavior. Defining mental health is important, although not always necessary to achieving its improvement. Differences in values across countries, cultures, classes and genders can appear too great to allow a consensus definition. ${ }^{[1]}$ 
The word psychosis is used to describe conditions that affect the mind, where there has been some loss of contact with reality. When someone becomes ill in this way it is called a psychotic episode. During a period of psychosis, a person's thoughts and perceptions are disturbed and the individual may have difficulty understanding what is real and what is not. Symptoms of psychosis include delusions (false beliefs) and hallucinations (seeing or hearing things that others do not see or hear). As well as these so called positive symptoms, negative symptoms such as affective blunting and loss of motivation can also occur. In addition, there are many other secondary features such as depression, anxiety, sleep disturbance, social withdrawal and impaired role functioning during a psychotic episode. It is these features which often provide the clue to the presence of psychosis. ${ }^{[2]}$

A pathway study is a quick, useful, and inexpensive method of clarifying the way in which individuals with mental health problems seek help. The first multicenter pathway study was conducted in 1991 by WHO under the supervision of Gater et al. ${ }^{[3]}$ This study has shown that pathways to mental health care are influenced by multiple factors, including conventions, governing referral systems, relationships between mental health services and other sources of help, and the availability and accessibility of mental health agencies and other agencies.

Pathway of care is defined as the sequence of contacts with individuals and organizations, initiated by the distressed person's efforts and those of his significant others to seek appropriate help..$^{[4]}$ In other words, pathway of care is an outline of anticipated care, placed in an appropriate timeframe, to help a patient with a specific condition or set of symptoms move progressively through a clinical experience to positive outcomes.

Trivedi and Jalini (2011) discuss the effectiveness and determinant of pathways of care as the basic purpose of the pathway of care is to provide early engagement with psychiatric services to minimize the effective cost of treatment and maximize better prognosis. $^{[5]}$

In other words, Pathway of care is an outline of predictable care, placed in an appropriate timeframe, to help a patient with a specific condition or set of symptoms move progressively through a clinical experience to positive outcomes. Psychiatric services are limited in developing countries like India, even at places where they are available and among those who could have easier access to avail benefits early from psychiatric services. Significant number of patients find psychiatric services as the last resort after having consultations from many different types of non-psychiatric care providers. ${ }^{[1]}$ This has increased the importance of not only the availability of mental health services in the community for easier access but also the various social and cultural factors which determine the help seeking behavior and pathway of psychiatric care. It is defined as the sequence of contacts with individuals and organizations, initiated by the distressed person's efforts and those of his significant others to seek appropriate help. ${ }^{[4]}$

There have been several factors that have been considered as the possible reasons for undesirable delay to access psychiatric treatment. Factors causing delay in the initiation of appropriate treatment vary from region to region depending upon that region's sociocultural profile, education, attitude of family, society's attitude toward mental illness, perceptions, myths, beliefs, stigma attached with psychiatric disorder, availability, accessibility of psychiatric services and referral patterns. As already replicated in many studies, the longer the DUP, the poorer is the quality of life and outcome. ${ }^{[6]}$ These determinants play an important role in deciding the pathway of care in different geographic regions of the world. There is also a significant role of care providers in deciding the pathways to psychiatric care, the first care provider being the most important for giving direction to the pathway of care to seek further help. ${ }^{[7]}$ 
Pathways of Psychiatric Treatment in Rural Patients with Psychosis

\section{OBJECTIVES OF THE STUDY :}

To examine the various pathways of psychiatric treatment in rural patients with psychosis and to know the source of referral, first contact for treatment, awareness about the signs and symptoms and various symptoms (complains) with which the patients presented themselves to the different modalities of treatment.

\section{METHODOLOGY}

\section{Design of the Study :}

It was a cross sectional hospital based study on patients who were contacting mental health professionals for the first time during a month.

\section{Sample :}

Purposive sampling technique was used for the study. The patients who were fulfilling screening criteria in the last one month were selected for the study. A total of 96 participants were selected for the study.

\section{Venue of the study:}

This study was conducted at Out-Patient Department of Ranchi Institute of Neuro-Psychiatry \& Allied Sciences (RINPAS) Kanke, Ranchi. The respondents were the primary caregivers of the patient (i.e. the person who taking the responsibility for care of the patient and is a member of the family, and living with patient at least for last two years).

\section{Inclusion Criteria :}

1. Patients diagnosed with psychosis as per ICD 10 DCR (1993)

2. Patients who attended with the caregivers having detailed information regarding patient's illness since onset.

3. Caregivers who have been staying with patient for last two years.
4. Patients attending a mental health professional (preferably psychiatrist) for the first time

5. Age $18 \&$ above.

6. No significant family history of psychiatric illness.

7. Caregivers giving written consent for being part of the study.

\section{Exclusion Criteria :}

1. Patients who were not attending with caregivers or family members.

2. Patients who are coming for follow up.

3. Patients who belong to urban and semi urban areas.

\section{Study Tools :}

a) Socio demographic and clinical data sheet was prepared for this study. It had various socio-demographic variables of caregivers and patients such as name, educational qualification, occupation, marital status, socioeconomic status, religion, area of residence, type of the family and family income per month. Clinical information included age of onset, course of illness, progress of illness and diagnosis.

b) The pathways study: encounter form (WHO, 1987) : It was developed by WHO and checked by Gater et al.

c) Brief Psychiatric Rating Scale (BPRS) (Overall and Gorham, 1962) : It is a comprehensive 24-item symptoms scale. Rating of items 1 through 14 are based on patients' self-report during the clinical interview. Items 7, 12, 17 are also rated on observed behavior during the interview. Rating of items 15 through 24 are based on patients' observed behavior or speech during the interview.

\section{PROCEDURE :}

Those who had fulfilled screening test were selected for the study. 96 participants were selected for the 
study, after that a detailed explanation was given to the participants about the purpose of the study and then informed consent was obtained. Information regarding socio demographic and clinical variables was collected on socio demographic and clinical data sheet from caregivers. Initially severity of patients' psychiatric symptoms were checked using Brief Psychiatric Rating Scale (BPRS). After that caregivers werre interviewed by using WHO pathways encounter form to know pathways to treatment in rural patients with psychosis.

\section{Statistical Analysis :}

The appropriate analysis was done using the statistical package for social science, version 20 (SPSS-20).

\section{RESULT :}

Table 1 shows that the mean age of patient was $32.21 \pm 13.48$ years and mean duration of illness was $558.80 \pm 707.08$ days . Majority of the patients were males $(71.9 \%)$ and Hindu (89.6\%). Most of them were housewives $(29.2 \%)$ by occupation, 2 nd major occupation was labor (15.6\%) and business/selfemployed (15.6\%). Majority belonged to a nuclear family $(82.3 \%)$. Most of the patients had family income below 10000 (87.5\%).

Table 2 shows that $100 \%$ of patients had a continuous course and a deteriorating progress of illness. The diagnosis of majority of patients was schizophrenia (37.5\%), unspecified non-organic psychosis (25.0\%) and Cannabis dependence syndrome (CDS) with psychosis (12.5\%).

Table 3 shows that first symptoms appear at onset of illness, in which fearfulness (13.5\%) appear in most patients followed by decreased talk (11.5\%). About $1 \%$ had poor personal hygiene, perceptual disturbance, unusual thought and disturbed work.

Table 4 shows how long they have taken to decide for consultation. They have taken a mean $417.67 \pm 621.11$ days to seek help in which first consultation was to native \& faith healers in most $(69.8 \%)$ followed by psychiatric services (17.7\%). Disturbed sleep (33.3) was most and suspiciousness (15.6) was second most cause of consultation. The treatment offered in first consultations was faith healing $(67.7 \%)$ in most followed by others. (See Figure- 1)

Table 5 shows the symptoms at first contact with native/religious healers, psychiatric services, general hospital and medical practitioners. At contact withy native/religious healers the most common symptoms were decreased talk (23.9\%) and disturbed sleep (35.8\%). For the psychiatric services, most common symptoms were disturbed sleep (35.3\%) and suspiciousness (35.3\%) and muttering to self $(28.4 \%)$. Decreased talk ( $40 \%$ ) was most common symptom for consultation to general hospital and assaultive behavior, muttering to self and perceptual disturbance were the most common symptoms for consultation with medical practitioners.

Table 6 shows first referral and how long they have taken to decide for consultation by first referral. Mean $67.25 \pm 22.52$ days were taken to seek help by first referral, in which first referral was to psychiatric services in most (64.6\%) and followed by native / religious healers (6.3\%). The neighbors initiated most of first referrals $(39.6 \%)$ and second most referrals were initiated by relatives / friends (34.4), in which disturbed sleep $(27.1 \%)$ was most and suspiciousness $(19.8 \%)$ second most cause of consultation. The treatment offered in first referral was psychiatric service $(67.7 \%)$ in most and then others. (See Figure- 1)

\section{DISCUSSION}

The present study used a cross-sectional design and patients are selected using a purposive sampling technique. A total of 96 patients were selected for the study during a month. There are published studies on pathways to psychiatric care but not focusing on rural patients and the attitude of caregivers regarding mental illness. But some of the studies published on pathways to psychiatric care used similar methodology in India and many 
Pathways of Psychiatric Treatment in Rural Patients with Psychosis

countries. In one such study pathways to psychiatric care in South India and their socio-demographic and attitudinal correlates, the researcher conducted among 104 consecutive, newly registered consenting patients/informants presenting to the Outpatient clinic of a Tertiary hospital in Mysore over 2 months. WHO Encounter form was used to obtain Socio-Demographic details and referral patterns. Diagnosis was made based on ICD-10. ${ }^{[8]}$ Further in our study, Brief Psychiatric Rating Scale was used to assess the severity of psychosis which is not done in another study.

In our study, the mean age of the patients at the time of first time consultation with psychiatric was $32.21 \pm 13.48$ years. In terms of gender, majority of the patients were males (71.9\%); this could be just a representation of utilization of the hospital services by male patients as compared to female patients. Similarly, Lahariya et al (2010) support the study finding. [9]Further, $89.6 \%$ patients were Hindu by religion and this could be explained as Hindu is the religion of majority in India. Similarly, Jain et al (2012) reported that $92 \%$ of their patients were Hindu by religion.[10] Another study done by Reddy et al (2017) reported that $80.6 \%$ patients were Hindus. ${ }^{[11]}$

In our study $22.9 \%$ patients were illiterate and $31.3 \%$ patients were educated up to primary level. $82.2 \%$ had a nuclear family. $81.5 \%$ patient's family income was below 10000 . Housewife $(29.2 \%)$ was the main occupation for female patients and for the male patients self-employed (15.6\%) and labor (15.6\%) than unemployed $(12.5 \%)$ and student $(12.5 \%)$ was the main occupation. Reason could be that in the present scenario, most of the families are of nuclear type, all of the patients are from rural background and come from lower socio-economic status. Similarly, Reddy et al (2017) reported that 65.3\% patients belong to nuclear family and $91.7 \%$ patients belong to low socio-economic status. Hashimoto et al (2010) reported that the 3 largest occupational categories were housewives $(25.6 \%)$, unemployed $\left(23^{\prime} 3 \%\right)$, and students $(18.6 \%) .^{[1]}$
It was seen that $100 \%$ patients had continuous course and deteriorating progress of illness. In terms of diagnosis of the patients as the first most common illness reported was schizophrenia (37.5\%) and second common diagnosis was unspecified nonorganic psychosis $(25.0 \%)$. In contrast, Chan et al (2014) reported that first common diagnosis was neurotic, stress related somatoform disorder and Hashimoto et al (2010) also reported that in his study neurotic, stress-related, and somatoform neurotic disorders were the most frequent diagnoses accounting for $33.7 \%$ of the diagnoses. ${ }^{[12][13]}$ However, the current sample consisted of patients with psychosis only and excluded those with neurotic and stress related disorders. Hence the schizophrenia was found as the most commonly presented disorder.

In our study the duration of untreated psychosis was $558.80 \pm 707.08$ days. In contrast, Naqvi et al (2009) found that DUP was 14.8 months and another study done by Sharifi et al (2009) found that DUP was 11 weeks. ${ }^{[14][15]}$ The reason for the difference of the results could be the differing role played by the family members, socio demographic characteristics, culture beliefs of the patients and the attitude and stigma prevailing in the society.

It was seen that fearfulness was the most common symptom reported by the patients when their illness had started in initial stage. Decreased talk and disturbed sleep were second and third common symptoms for initial stage. The first symptom as was subjectively described by the caregiver of the patient, has not been previously categorized or mentioned in past literatures on similar work.

It was seen in first contact with native/religious healers, the most common symptoms were decreased talk (23.9\%), aggressive and abusive behavior (23.9), muttering to self $(17.9 \%)$ and irrelevant talk $(17.9 \%)$. But disturbed sleep (35.8\%) was reported in every case. The least common symptoms were disorders of thinking, disorders of perception, restlessness, smiling to self and suicidal attempt in about $1.5 \%$. For 
the psychiatric services, most common symptoms were disturbed sleep (35.3\%), suspiciousness (35.3\%) and muttering to self $(28.4 \%)$. Decreased talk $(40 \%)$ was most common symptom for consultation to general hospital and assaultive behavior, muttering to self and perceptual disturbance were the symptoms for consultation with medical practitioners.

For the psychiatrist service, most common symptoms were disturbed sleep (35.3\%) and suspiciousness (35.3\%) and muttering to self $(28.4 \%)$ and disorganized behavior (17.6\%) were second and third common symptoms. In contrast Reddy et al (2017) reported that at the time of psychiatric consultation, disorders of thought and perception seen in > $90 \%$ patients. ${ }^{[11]}$ Another study by Pradhan et al (2001), reported that at the time of psychiatric consultation mostly patients presented with somatic symptoms. ${ }^{[16]}$ Another study by Naqvi et al (2009) reported auditory hallucinations $(61 \%)$ and delusions of persecution $(43 \%)$ as the main symptoms in consultation with psychiatric services. ${ }^{[14]}$ The reason for such different findings could be attributed to the fact that these researchers have used structured questionnaires to assess for the presenting symptoms which was not used in the current study. This study used a subjective interview to inquire about the chief presenting complaints that were mentioned by the caregivers.

It was seen that the time taken to decide to go for a consultation after onset of illness was $417.67 \pm 621.11$ days, in which first consultation was to native \&faith healers mostly $(69.8 \%)$ followed by psychiatric services (17.7\%). A study by Kurihara et al., (2006) provides similar findings where the pathway to psychiatric care was also dominated by faith healers. ${ }^{[17]}$ The first source of treatment chosen by the subjects were traditional healers. Another study by Hashimoto et al (2010) provides similar finding, individuals with psychotic disorders most frequently selected native or religious healers.[13] Another study by Reddy et al (2017) found that the most common first modality of treatment was by faith healers $(61.1 \%)$ and reported that $20 \%$ patients consult to the psychiatric directly. ${ }^{[11]}$ The point of concern is that in developing countries, most patients do seek help from faith healers or local practitioners including quacks, but very few patients are referred to psychiatric services by them. ${ }^{[17][18]}$

In the first contact, $17.7 \%$ patients consulted psychiatrists directly. A study by Pradhan et al (2001) found contrast finding, among all five centers, a distinct finding from Kerala was reported that $74 \%$ of the people had directly come to the psychiatrist as their first contact. ${ }^{[16]}$ This could be attributed to the higher literacy status and mental health awareness in the state as a whole

For the first referral, it was seen that $64.6 \%$ patients consulted psychiatric service rather than the native / faith healer, general hospital and medical practitioner. The neighbours initiated first referral in $39.6 \%$ followed by relatives / friends (34.4). Similarly, Reddy et al (2017) found that most common shifting modality was from faith healing to psychiatric treatment (58.3\%) and in contrast, the most common source of referral to psychiatric care were relatives (73.6\%). In contrast, a study from south Manchester by Gater and Goldberg (1991) of 250 patients newly referred to the mental illness services of South Manchester, almost two-thirds were referred directly by their General Practitioners and a further third were referred by hospital doctors. Non-medical sources of referral accounted for only $2 \%$ of new cases. ${ }^{[19]}$ A study titled "Help seeking behavior of psychiatric patients before seeking care at a mental hospital at Delhi by Chadda et al ${ }^{[20]}$ reported that Psychiatrists were the first doctors to be consulted by the majority $(57.7 \%)$ of the patients for their mental illness followed by faith healers $(29.5 \%)$, alternative systems of medicine $(1.3 \%)$, and physicians (11.5\%).

The rating of severity of the psychiatric problems of the patients from rural background in the study was reported severe as mean score was 116.20 with SD 18.28. The minimum standard deviation all the participant more or less more than average severity 
Pathways of Psychiatric Treatment in Rural Patients with Psychosis

(midline marks 84). The scale was applied in the study to know the psychiatric problem prevalence in the commuted pathways.

\section{CONCLUSION}

The current study provides an insight into the nature of the pathway and referral taken by rural patients with psychosis and their caregivers while deciding the course of treatment to seek for mental health problems. It also elucidates the most common symptoms for which treatment is sought by the rural community. All the patients were taking first time consultation at tertiary care, had continuous course, insidious onset and deteriorating progress. The average duration of illness was 1.6 years and they had taken decision in 1.1 years (average) for treatment. Most of the patients went to faith healers. But in first referral itself most patient gone to the psychiatrist or tertiary mental health care institution; remaining patients finally went to tertiary care institute or mental health professionals at second referral itself.

\section{CLINICAL IMPLICATION \& LIMITATION}

The severity of cases is associated with duration of illness hence it is important to reduce the duration of illness. So the study would give insight about how they reach to the specialized care centers. In the study we have seen that if Faith Healers are trained enough to assess mental health issues they may refer cases of mental illness in first place to psychiatric center. The middle and important bond between patient and specialized professionals is general health practitioners so they should be trained for immediate or emergency care. If we include awareness that focusses on signs \& symptoms, that would be more effective. The rural patients with psychosis have more belief in Faith Healers. So Faith Healers could be included in awarenesss programmes. The present study was conducted on a small sample size and only rural patients therefore results cannot be generalized \& the sample was only taken from psychosis patients. This study was a hospital based cross sectional study \& only those patients who came to utilize the hospital services were assessed.

\section{REFERENCES}

1. World Health Organization. The World Health Report 2001 : Mental health : new understanding, new hope. World Health Organization; 2001.

2. National Institute of Mental Health. The National Institute of Mental Health Strategic Plan Bethesda, MD National Institute of Mental Health 2007 (NIH Publication 08-6368).

3. Gater R, Sousa DB, Barrientos G, Caraveo J, Chandrashekar CR, Dhadphale M, Goldberg D, Al Kathiri AH, Mubbashar M, Silhan K, Thong D. The pathways to psychiatric care : a cross-cultural study. Psychological medicine. 1991 Aug; 21(3) : 761-74.

4. Rogler LH, Cortes DE. Help-seeking pathways : a unifying concept in mental health care. The American Journal of Psychiatry. 1993 Apr 1; 150(4) : 554.

5. Trivedi JK, Jilani AQ. Pathway of psychiatric care. Indian journal of psychiatry. 2011 Apr; 53(2) : 97.

6. Franz L, Carter T, Leiner AS, Bergner E, Thompson NJ, Compton MT, et al. Stigma and treatment delay in firstepisode psychosis : A grounded theory study. Early Interv Psychiatry 2010; 4 : 47-56

7. Lincoln C, Harrigan S, Mcgorry PD. Understanding the topography of early psychosis pathways; an opportunity to reduce delays in treatment. Br J Psychiatry. 1998; 172 : 21-5.

8. Faizan S, Raveesh BN, Ravindra LS, Sharath K. Pathways to psychiatric care in South India and their socio-demographic and attitudinal correlates. In BMC proceedings $2012 \mathrm{Jul}$ (Vol. 6, No. 4, p. P13). Bio Med Central.

9. Lahariya C, Singhal S, Gupta S, Mishra A. Pathway of care among psychiatric patients attending a mental health institution in central India. Indian journal of psychiatry. 2010 Oct; 52(4) : 333.

10. Jain N, Gautam S, Jain S, Gupta ID, Batra L, Sharma R, Singh H. Pathway to psychiatric care in a tertiary mental health facility in Jaipur, India. Asian journal of psychiatry. $2012 \mathrm{Dec}$ $1 ; 5(4): 303-8$.

11. Reddy S, Sinha VK, SWAIN M, Prasad K, Pathways to psychiatric care in children and adolescents with first episode psychosis. Social Sciences International Research Journal 2017. 3 (2), 57-64.

12. Chan WC, Chow PP, Lam LC, Hung SF, Cheung EF, Dunn EL, Ng MK, Fu JC. Pathway of psychiatric care in Hong Kong. Hong Kong Medical Journal. 2015.

13. Hashimoto N, Fujisawa D, Giasuddin NA, Kenchaiah BK, Narmandakh A, Dugerragchaa K, Tamrakar SM, Adhikari SR, Sartorius N. Pathways to mental health care in Bangladesh, India, Japan, Mongolia, and Nepal. Asia Pacific Journal of Public Health. 2015 Mar; 27(2) : NP1847-57. 


\section{Pathways of Psychiatric Treatment in Rural Patients with Psychosis}

14. Naqvi HA, Hussain S, Zaman M, Islam M. Pathways to care: duration of untreated psychosis from Karachi, Pakistan. PLoS One. 2009 Oct 12; 4(10) : e7409.

15. Sharifi, V., Kermani Ranjbar, T., Amini, H., Alaghband rad, J., Salesian, N., \& Seddigh, A. Duration of untreated psychosis and pathways to care in patients with first episode psychosis in Iran. Early Intervention in Psychiatry. 2009, 3(2), 131-136.

16. Pradhan, S.C., Das, Kothari, S., Agarwal, S., Mishra, R., Sailo, L. \& Ram, D. Pathways to psychiatric care : An Eastern Indian Experience. Indian Journal of Psychiatric. 1997 april. Vol. 39.
17. Kurihara T, Kato M, Reverger R, Tirta IG. Pathway to psychiatric care in Bali. Psychiatry and ClinicalNeurosciences. 2006 Apr; 60(2) : 204-10.

18. Jilani AQ, Trivedi JK, Dalal PK, Sinha PK, Dhyani M. Pathway of care in first episode non affective psychosis. Department of Psychiatry, CSMMU, Lucknow, India (Thesis submitted). 2009.

19. Gater R, Goldberg D. Pathways to psychiatric care in South Manchester. The British Journal of Psychiatry. 1991 Jul; 159(1) : 90-6.

20. Chadda RK, Agarwal V, Singh MC, Raheja D. Help seeking behaviour of psychiatric patients before seeking care at a mental hospital. International Journal of Social Psychiatry. 2001 Dec; 47(4) : 71-8. 
Pathways of Psychiatric Treatment in Rural Patients with Psychosis

Table - 1 : Frequency Distribution of the Socio Demographic Characteristics of the Patients

\begin{tabular}{|c|c|c|c|c|}
\hline \multicolumn{2}{|r|}{ S. No. } & Continuous Variable & \multicolumn{2}{|c|}{ Mean \pm SD } \\
\hline \multicolumn{2}{|r|}{1.} & Age (year) & \multicolumn{2}{|c|}{$32.21 \pm 13.48$} \\
\hline & 2. & Duration of illness (days) & \multicolumn{2}{|c|}{$558.80 \pm 07.08$} \\
\hline \multirow{2}{*}{\multicolumn{3}{|c|}{ Categorical variable }} & \multicolumn{2}{|c|}{$\mathrm{N}=96$} \\
\hline & & & $\mathbf{n}$ & $\%$ \\
\hline \multirow[t]{2}{*}{3.} & \multirow{2}{*}{ Gender } & Male & 69 & 71.9 \\
\hline & & Female & 27 & 28.1 \\
\hline \multirow[t]{3}{*}{4.} & \multirow{3}{*}{ Religion } & Hindu & 86 & 89.6 \\
\hline & & Muslim & 8 & 8.3 \\
\hline & & Christian & 2 & 2.1 \\
\hline \multirow[t]{5}{*}{5.} & \multirow{5}{*}{ Education } & Illiterate & 22 & 22.9 \\
\hline & & Primary & 30 & 31.3 \\
\hline & & Middle & 17 & 17.7 \\
\hline & & Secondary & 16 & 16.7 \\
\hline & & Above secondary & 11 & 11.5 \\
\hline \multirow[t]{2}{*}{6.} & \multirow{2}{*}{ Family type } & Nuclear & 79 & 82.3 \\
\hline & & Joint & 17 & 17.7 \\
\hline \multirow[t]{7}{*}{7.} & \multirow{7}{*}{ Occupation } & Unemployed & 12 & 12.5 \\
\hline & & Student & 12 & 12.5 \\
\hline & & Farmer & 9 & 9.4 \\
\hline & & Business / self employed & 15 & 15.6 \\
\hline & & Housewife & 28 & 29.2 \\
\hline & & Labor & 15 & 15.6 \\
\hline & & Professional & 5 & 5.2 \\
\hline \multirow[t]{4}{*}{8.} & \multirow{4}{*}{ Family income } & Less than 5000 & 20 & 20.8 \\
\hline & & 5000-10000 & 64 & 66.7 \\
\hline & & $10000-15000$ & 9 & 9.4 \\
\hline & & Above 15000 & 3 & 3.1 \\
\hline
\end{tabular}


Pathways of Psychiatric Treatment in Rural Patients with Psychosis

Table-2 : Clinical Characteristics of the Patients

\begin{tabular}{|c|c|c|c|c|}
\hline \multirow{2}{*}{ Sr. No. } & \multirow{2}{*}{ Variable } & & \multicolumn{2}{|c|}{$\mathrm{N}=96$} \\
\hline & & & $\mathbf{N}$ & $\%$ \\
\hline 1. & Course of illness & Continuous & 96 & 100 \\
\hline 2. & Progress of illness & Deteriorating & 96 & 100 \\
\hline \multirow{7}{*}{3.} & \multirow{7}{*}{ Diagnosis } & Mania with psychotic symptoms & 8 & 8.3 \\
\hline & & ADS with psychosis & 9 & 9.4 \\
\hline & & CDS with psychosis & 12 & 12.5 \\
\hline & & schizophrenia & 36 & 37.5 \\
\hline & & Unspecified Non-Organic Psychosis & 24 & 25.0 \\
\hline & & Severe depression with psychosis & 4 & 4.2 \\
\hline & & Acute and transient psychotic disorder & 3 & 3.1 \\
\hline
\end{tabular}

Table - 3 : The First Symptoms developed in the Patients

\begin{tabular}{|c|l|c|c|}
\hline \multirow{2}{*}{ Sr. No. Symptoms } & & \multicolumn{2}{c|}{ N=96 } \\
\cline { 3 - 4 } & & 7 & 7 \\
\hline 1. & Irrelevant talk & 5 & 7.3 \\
\hline 2. & Excessive talk & 11 & 8.3 \\
\hline 3. & Disturbed sleep & 13 & 11.5 \\
\hline 4. & Decreased talk & 8 & 13.5 \\
\hline 5. & Fearness & 1 & 8.3 \\
\hline 6. & Disorganized behavior & 7 & 1.0 \\
\hline 7. & Poor personal hygiene & 6 & 7.3 \\
\hline 8. & Assaultive behavior & 8 & 6.3 \\
\hline 9. & Aggressive and abusing behavior & 4 & 8.3 \\
\hline 10. & Wandering behavior & 3 & 4.2 \\
\hline 11. & Muttering to self & 1 & 3.1 \\
\hline 12. & Disorder of thinking & 7 & 1.0 \\
\hline 13. & Perceptual disturbance & 1 & 7.3 \\
\hline 14. & Suspiciousness & 1 & 1.0 \\
\hline 15. & Unusual thought & 3 & 1.0 \\
\hline 16. & Disturbed work & & 2.1 \\
\hline 17. & Disturbed appetite & 3.1 \\
\hline 18. & Smiling to self & & \\
\hline
\end{tabular}


Pathways of Psychiatric Treatment in Rural Patients with Psychosis

Table - 4 : The Decision to First Seek Help

\begin{tabular}{|c|c|c|c|c|}
\hline Sr. No. & \multicolumn{2}{|c|}{ Domain } & \multicolumn{2}{|c|}{ Mean \pm SD } \\
\hline 1. & \multicolumn{2}{|c|}{ How long-ago decision to first seek help } & \multirow{2}{*}{\multicolumn{2}{|c|}{$\begin{array}{c}417.67 \pm 621.11 \\
\mathbf{N}=96\end{array}$}} \\
\hline \multirow[t]{2}{*}{2.} & & \multirow{2}{*}{ Response } & & \\
\hline & & & $\mathbf{N}$ & $\%$ \\
\hline \multirow{4}{*}{3.} & \multirow{4}{*}{ Who was the first seen } & Native/ religious healer & 67 & 69.8 \\
\hline & & Medical practitioner & 2 & 2.1 \\
\hline & & General hospital & 10 & 10.4 \\
\hline & & Psychiatric service & 17 & 17.7 \\
\hline \multirow{3}{*}{4.} & \multirow{3}{*}{ Who initiated first contact } & Patients himself & 65 & 67.7 \\
\hline & & Relative / friends & 12 & 12.5 \\
\hline & & Neighbors & 19 & 19.8 \\
\hline \multirow{21}{*}{5.} & \multirow{21}{*}{$\begin{array}{l}\text { What symptoms caused } \\
\text { decision to seek care }\end{array}$} & Irrelevant talk & 15 & 15.6 \\
\hline & & Excessive talk & 2 & 2.1 \\
\hline & & Disturbed sleep & 32 & 33.3 \\
\hline & & Decreased talk & 21 & 21.9 \\
\hline & & Fearfulness & 13 & 13.5 \\
\hline & & Disorganized behavior & 15 & 15.6 \\
\hline & & Poor personal hygiene & 11 & 11.5 \\
\hline & & Assaultive behavior & 15 & 15.6 \\
\hline & & Aggressive and abusing behavior & 18 & 18.8 \\
\hline & & Wandering behavior & 15 & 15.6 \\
\hline & & Muttering to self & 19 & 19.8 \\
\hline & & Disorder of thinking & 3 & 3.1 \\
\hline & & Perceptual disturbance & 2 & 2.1 \\
\hline & & Suspiciousness & 15 & 15.6 \\
\hline & & Unusual thought & 3 & 3.1 \\
\hline & & Restlessness & 1 & 1.0 \\
\hline & & Low memory & 2 & 2.1 \\
\hline & & Negative thinking & 1 & 1.0 \\
\hline & & Suicidal attempt & 4 & 4.2 \\
\hline & & Disturbed work & 3 & 3.1 \\
\hline & & Smiling to self & 1 & 1.0 \\
\hline \multirow{4}{*}{6.} & \multirow{4}{*}{ What treatment was offered } & Faith healing & 65 & 67.7 \\
\hline & & Traditional medicine & 2 & 2.1 \\
\hline & & General medicine & 11 & 11.5 \\
\hline & & Psychiatric medicine & 18 & 18.8 \\
\hline
\end{tabular}


Pathways of Psychiatric Treatment in Rural Patients with Psychosis

Table - 5 : Symptoms Present when the Patient first seeked help from Native/Religious healer, Psychiatric Service, Medical Practitioner and General Hospital.

\begin{tabular}{|c|c|c|c|c|c|c|c|c|c|}
\hline \multirow{3}{*}{ Sr. No. } & \multirow{3}{*}{$\begin{array}{c}\text { Symptoms } \\
\text { (first seek help) }\end{array}$} & \multirow{2}{*}{\multicolumn{2}{|c|}{$\begin{array}{c}\begin{array}{c}\text { Native/ } \\
\text { religious healer }\end{array} \\
\mathbf{N}=\mathbf{6 7}\end{array}$}} & \multirow{2}{*}{\multicolumn{2}{|c|}{$\begin{array}{c}\begin{array}{c}\text { Psychiatric } \\
\text { service }\end{array} \\
\mathbf{N}=\mathbf{1 7}\end{array}$}} & \multirow{2}{*}{\multicolumn{2}{|c|}{$\begin{array}{c}\begin{array}{c}\text { General } \\
\text { hospital }\end{array} \\
\mathbf{N = 1 0}\end{array}$}} & \multirow{2}{*}{\multicolumn{2}{|c|}{$\begin{array}{c}\begin{array}{c}\text { Medical } \\
\text { practitioner }\end{array} \\
\mathbf{N}=\mathbf{2}\end{array}$}} \\
\hline & & & & & & & & & \\
\hline & & $\mathbf{N}$ & $\%$ & $\mathbf{N}$ & $\%$ & $\mathbf{N}$ & $\%$ & $\mathbf{N}$ & $\%$ \\
\hline 1. & Irrelevant talk & 12 & 17.9 & 1 & 5.9 & 2 & 20.0 & & \\
\hline 2. & Excessive talk & 2 & 3.0 & & & & & & \\
\hline 3. & Disturbed sleep & 24 & 35.3 & 6 & 35.3 & 2 & 20.0 & & \\
\hline 4. & Decreased talk & 16 & 23.9 & 1 & 5.9 & 4 & 40.0 & & \\
\hline 5. & Fearfulness & 11 & 16.4 & 2 & 11.8 & & & & \\
\hline 6. & Disorganized behavior & 11 & 16.4 & 3 & 17.6 & 1 & 10.0 & & \\
\hline 7. & Poor personal hygiene & 8 & 11.9 & 2 & 11.8 & 1 & 10.0 & & \\
\hline 8. & Assaultive behavior & 8 & 11.9 & 4 & 23.5 & 1 & 10.0 & 2 & 100 \\
\hline 9. & $\begin{array}{l}\text { Aggressive and abusing } \\
\text { behavior }\end{array}$ & 16 & 23.9 & & & 1 & 10.0 & & \\
\hline 10. & Wandering behavior & 11 & 16.4 & 2 & 11.8 & 2 & 20.0 & & \\
\hline 11. & Muttering to self & 12 & 17.9 & 5 & 28.4 & 1 & 10.0 & 1 & 50 \\
\hline 12. & Disorder of thinking & 1 & 1.5 & 2 & 11.8 & & & & \\
\hline 13. & Perceptual disturbance & 1 & 1.5 & & & & & 1 & 50 \\
\hline 14. & Suspiciousness & 8 & 11.9 & 6 & 35.3 & 1 & 10.0 & & \\
\hline 15. & Unusual thought & 2 & 3.0 & 1 & 5.9 & & & & \\
\hline 16. & Restlessness & 1 & 1.5 & & & & & & \\
\hline 17. & Low memory & 2 & 3.0 & & & & & & \\
\hline 18. & Negative thinking & 1 & 1.5 & & & & & & \\
\hline 19. & Suicidal attempt & 1 & 1.5 & 2 & 11.8 & 1 & 10.0 & & \\
\hline 20. & Disturbed work & 2 & 3.0 & & & 1 & 10.0 & & \\
\hline 21. & Smiling to self & 1 & 1.5 & & & & & & \\
\hline
\end{tabular}


Pathways of Psychiatric Treatment in Rural Patients with Psychosis

Table - 6 : The First Referral

\begin{tabular}{|c|c|c|c|c|}
\hline Sr. No. & & Domain & \multirow{2}{*}{\multicolumn{2}{|c|}{$\begin{array}{l}\text { Mean } \pm \text { SD } \\
67.25 \pm 22.52 \\
\end{array}$}} \\
\hline 1. & \multicolumn{2}{|c|}{ How long-ago decision for first referral } & & \\
\hline \multirow{2}{*}{2.} & & \multirow{2}{*}{ Response } & & \\
\hline & & & $\mathbf{N}$ & $\%$ \\
\hline \multirow{4}{*}{3.} & \multirow{4}{*}{ Who was the next seen } & Native/religious healer & 6 & 6.3 \\
\hline & & Medical practitioner & 4 & 4.2 \\
\hline & & General hospital & 8 & 8.3 \\
\hline & & Psychiatric service & 62 & 64.6 \\
\hline \multirow{5}{*}{4.} & \multirow{5}{*}{ Decision taken by whom } & Patients himself & 5 & 5.2 \\
\hline & & Relative/friends & 33 & 34.4 \\
\hline & & Neighbors & 38 & 39.6 \\
\hline & & Medical practitioner & 2 & 2.1 \\
\hline & & Other (faith healer) & 2 & 2.1 \\
\hline \multirow{21}{*}{5.} & \multirow{21}{*}{$\begin{array}{l}\text { What symptoms caused } \\
\text { decision to seek } 1 \text { st referral }\end{array}$} & Irrelevant talk & 6 & 6.3 \\
\hline & & Excessive talk & 2 & 2.1 \\
\hline & & Disturbed sleep & 26 & 27.1 \\
\hline & & Decreased talk & 23 & 24.0 \\
\hline & & Fearfulness & 8 & 8.3 \\
\hline & & Disorganized behavior & 10 & 10.4 \\
\hline & & Poor personal hygiene & 26 & 27.1 \\
\hline & & Assaultive behavior & 7 & 7.3 \\
\hline & & Aggressive and abusing behavior & 7 & 7.3 \\
\hline & & Wandering behavior & 17 & 17.7 \\
\hline & & Muttering to self & 41 & 42.7 \\
\hline & & Disorder of thinking & 8 & 8.3 \\
\hline & & Perceptual disturbance & 5 & 5.2 \\
\hline & & Suspiciousness & 19 & 19.8 \\
\hline & & Unusual thought & 10 & 10.4 \\
\hline & & Weakness & 1 & 1.0 \\
\hline & & Negative thinking & 1 & 1.0 \\
\hline & & Suicidal attempt & 3 & 3.1 \\
\hline & & Disturbed work & 8 & 8.3 \\
\hline & & Disturbed appetite & 6 & 6.3 \\
\hline & & Smiling to self & 9 & 9.4 \\
\hline \multirow{3}{*}{6.} & \multirow{3}{*}{ What treatment was offered } & Faith healing & 6 & 6.3 \\
\hline & & General medicine & 12 & 12.5 \\
\hline & & Psychiatric medicine & 62 & 64.6 \\
\hline
\end{tabular}


Pathways of Psychiatric Treatment in Rural Patients with Psychosis

Tablel-7 : Severity of Psychiatric Symptoms in Rural Patients with Psychosis on the Brief Psychiatric Rating Scale (BPRS).

\begin{tabular}{|c|c|c|}
\hline Sr. No. & Variable & Mean \pm SD \\
\hline 1. & BPRS & $116.20 \pm 18.28$ \\
\hline
\end{tabular}

\section{Figure 1}

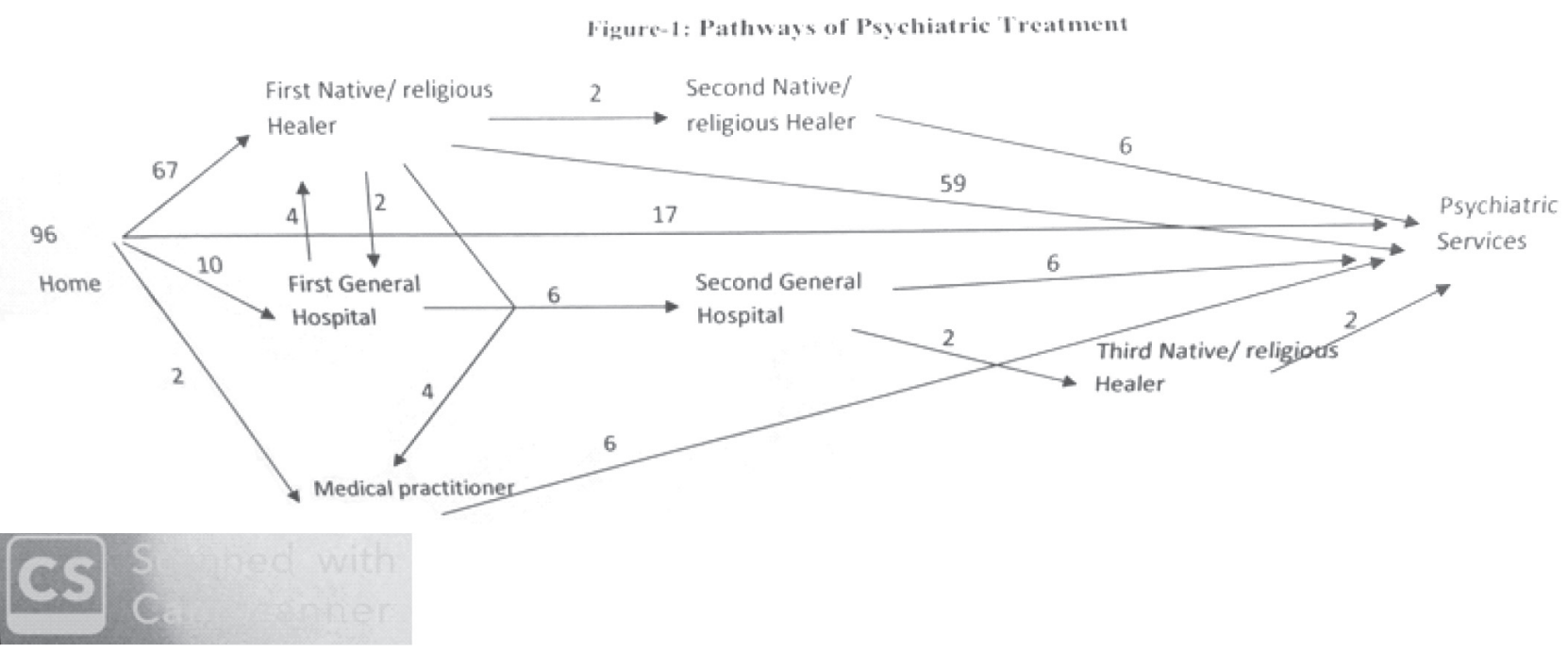

